CASE REPORTS

\title{
Villous papillomata of the large bowel associated with renal failure
}

\author{
J. N. KILLE \\ M.B.(Birm.), F.R.C.S. \\ Senior Urological Registrar \\ J. D. BLAINEY \\ M.D.(Lond.), F.R.C.P. \\ Consultant Physician
}

\author{
P. DaWSON-EDWARDS \\ M.B.(Birm.), F.R.C.S. \\ Consultant Surgeon
}

J. S. ELKINGTON
F.R.C.S.
Surgical Registrar
THE GROSS disturbances of biochemical and fluid balance associated with some cases of villous papillomata of the large bowel have been described in a number of reviews (Bacon, Lowell \& Trimpi, 1954 ; Shamblin et al., 1962; Davis, Seavey \& Sessions, 1962 ; Diffenbaugh et al., 1964 ; Bamford, Galbraith \& Pender, 1965). The case reports of two patients are presented and their management discussed.

\section{Case report 1}

A 56-year-old labourer was admitted to hospital with a 6-year history of attacks of diarrhoea, upper abdominal colic and vomiting. When he first complained of these symptoms a barium enema showed a redundant sigmoid colon with a markedly irregular mucosal pattern suggesting some polypoid change. A diagnosis of 'colitis' was made. Despite more frequent attacks of diarrhoea this patient remained at work until 3 days before admission, by which time he was passing large quantities of blood-stained fluid and mucus per rectum.

Examination revealed considerable muscle wasting and gross dehydration. Biochemical and haemotological investigations are shown in Table 1. A large volume of fluid was administered by mouth and intravenously until the urinary output had risen from $300 \mathrm{ml}$ in the first $24 \mathrm{hr}$ to 2 litres. On the 2nd day after admission a polypoid tumour prolapsed through the anus. Reduction required a general anaesthetic following which a postoperative pneumonia and a violent penicillin reaction led to a general deterioration in the patient's condition. By the 8th day his blood urea had climbed to $700 \mathrm{mg} / 100 \mathrm{ml}$ and he was transferred to the care of this unit with a diagnosis of villous papilloma of the rectum.

On admission he was semi-comatose but sufficiently rousable to answer simple questions. Physical signs included a persistent fine twitching of the limbs and generalized clonic convulsions occurr-

TABLE 1

Biochemical and haematological investigations on admission to hospital and to artificial kidney unit (A.K.U.)

\begin{tabular}{|c|c|c|c|c|c|c|c|c|c|c|}
\hline & \multicolumn{6}{|c|}{ Biochemical investigations } & \multicolumn{4}{|c|}{ Haematological investigation } \\
\hline & $\begin{array}{l}\text { Blood urea } \\
(\mathrm{mg} / 100 \mathrm{ml})\end{array}$ & $\begin{array}{l}\text { Elec } \\
\mathrm{Na}\end{array}$ & troly & $\begin{array}{c}\text { tes }(\mathrm{r} \\
\mathrm{Cl}\end{array}$ & $\begin{array}{l}\mathrm{mEq} / \mathrm{l}) \\
\mathrm{HCO}_{3}\end{array}$ & $\mathrm{pH}$ & $\begin{array}{c}\mathrm{PcO}_{2} \\
(\mathrm{mmHg})\end{array}$ & $\begin{array}{c}\mathrm{Hb} \\
(\mathrm{g} / 100 \mathrm{ml})\end{array}$ & $\begin{array}{l}\text { PCV } \\
(\%)\end{array}$ & $\begin{array}{l}\text { WBC } \\
\left(\mathrm{mm} \mathrm{3}^{3}\right)\end{array}$ \\
\hline $\begin{array}{l}\text { Case } 1 \\
\text { On admission: } \\
\text { To hospital } \\
\text { To A.K.U. }\end{array}$ & $\begin{array}{l}270 \\
700\end{array}$ & $\begin{array}{l}112 \\
138\end{array}$ & $\begin{array}{l}2.9 \\
3.9\end{array}$ & $\begin{array}{l}67 \\
96\end{array}$ & $\begin{array}{l}10 \\
25 \cdot 4\end{array}$ & $7 \cdot 4$ & 36 & $\begin{array}{l}14 \cdot 2 \\
14 \cdot 3\end{array}$ & 37 & $\begin{array}{l}14,600 \\
11,200\end{array}$ \\
\hline $\begin{array}{l}\text { Case } 2 \\
\text { On admission: } \\
\text { To hospital } \\
\text { To A.K.U. }\end{array}$ & $\begin{array}{l}330 \\
560\end{array}$ & 115 & $2 \cdot 7$ & 60 & 13 & $7 \cdot 2$ & 23 & $16 \cdot 0$ & 48 & 11,300 \\
\hline
\end{tabular}


ing every few minutes. His state of hydration was difficult to assess because of the weight loss and the presence of a fine desquamation of the skin due to the penicillin reaction. Pulse rate was $90 /$ min and blood pressure $145 / 80 \mathrm{mmHg}$, temperature $97^{\circ} \mathrm{F}$ and respiration 'acidotic' in type. Moist sounds were present in all areas of the chest. Serum calcium $3.6 \mathrm{mEq} / 1$, phosphorus $6.0 \mathrm{mEq} / 1$, uric acid $24.6 \mathrm{mg} / 100 \mathrm{ml}$, and blood sugar 188 $\mathrm{mg} / 100 \mathrm{ml}$. Other investigations, Table 1.

Immediate vein-to-vein haemodialysis using a Travenol Twin Coil artificial kidney was undertaken. The blood urea fell to $325 \mathrm{mg} / 100 \mathrm{ml}$, with some improvement in his general condition but little change in level of consciousness; in fact the patient was not considered 'well' until after the third haemodialysis and the administration of $14,600 \mathrm{ml}$ of fluid in excess of the measured output (calculated from fluid balance charts and the change in body weight). Management was complicated by a septicaemia and enteritis, confirmed by culture of blood and stool due to Staphylococcus aureus (coagulase positive) organisms. Details of his progress are represented in Fig. 1.
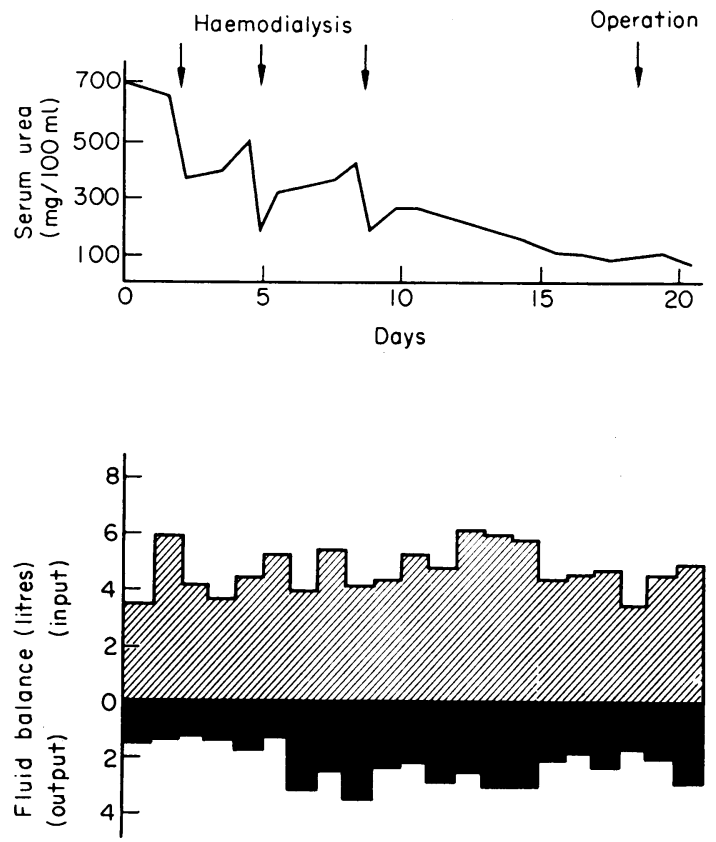

FIG. 1. Progress chart of Case 1. Cross-hatched area, fluid intake (excluding blood); solid area, urine volume.

Sigmoidoscopy showed that his tumour extended between 3 and $13 \mathrm{~cm}$ from the anal margin. Barium enema proved that it was the only lesion present.

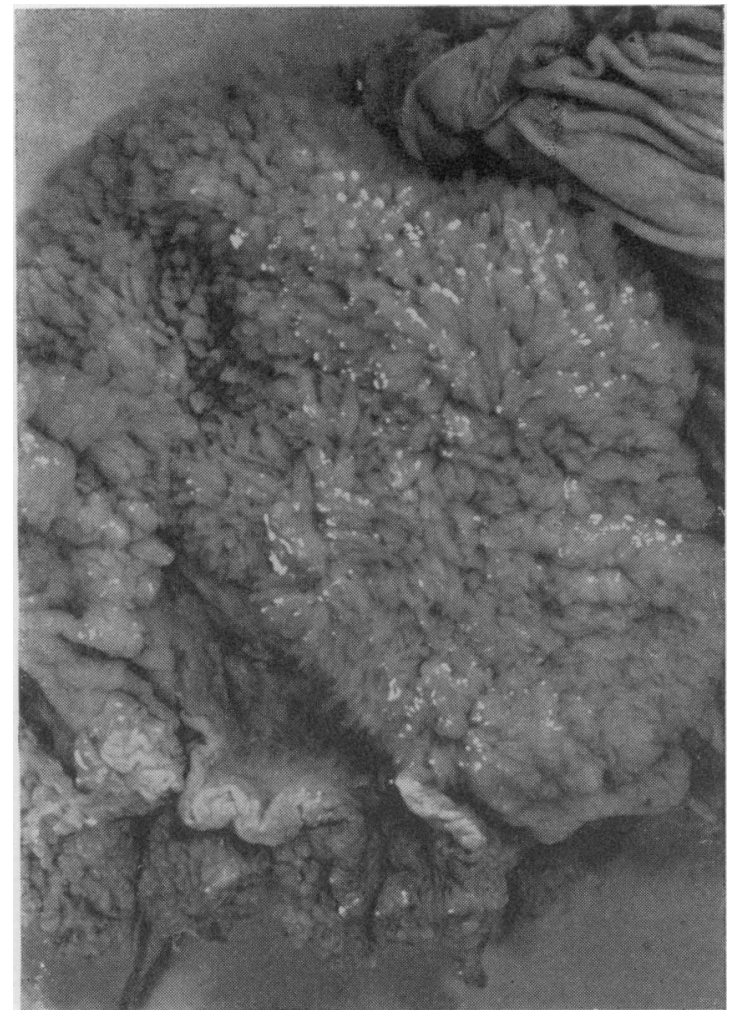

Fig. 2. Operative specimen (Case 1). Maximum diameter of the villous papilloma $13 \mathrm{~cm}$. Anal margin is visible $3 \mathrm{~cm}$ below the tumour.

Eighteen days after admission abdominoperineal resection of the rectum and tumour was performed (PDE); an uneventful recovery was made apart from a deep-vein thrombosis of the right leg.

The specimen removed (Fig. 2) included a papilliferous neoplasm situated in the lower part of the rectum almost completely encircling the lumen. Maximum diameter $13 \mathrm{~cm}$. Microscopic examination confirmed the diagnosis (Fig. 3).

\section{Case report 2}

A 60-year-old wheelwright was admitted to hospital with 6 days' nausea, vomiting and diarrhoea. He gave a 4-year history of attacks of diarrhoea that had been labelled as due to 'colitis'. No blood had been passed. The patient was dehydrated and oliguric with a blood urea of 330 $\mathrm{mg} / 100 \mathrm{ml}$. No abnormality was detected on abdominal or rectal examination. Two days later his blood urea had risen further and he was transferred to this unit.

On admission he was dehydrated and stuporous, responding only to forcible pin prick. His pulse 


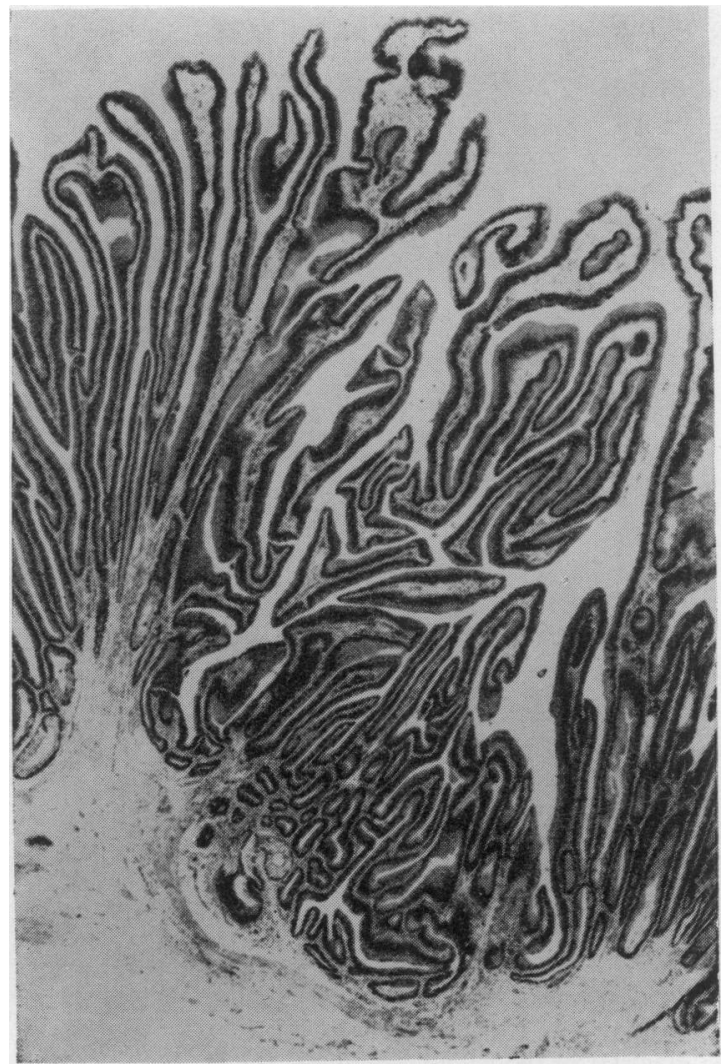

Fig. 3. Low power view of the villi (Case 1). The muscularis mucosa has been drawn up into the tumour but no evidence of malignancy was found.

rate was $80 / \mathrm{min}$ and blood pressure $120 / 90$ $\mathrm{mmHg}$. Respiration was acidotic in type and temperature $97^{\circ} \mathrm{F}$. Biochemical and haematological investigations are shown in Table 1.

Immediate vein-to-vein haemodialysis with the Travenol Twin Coil artificial kidney was carried out, when the blood urea fell from 560 to 250 $\mathrm{mg} / 100 \mathrm{ml}$ with some improvement in the patient's general condition but little change in his level of consciousness. He remained oliguric and haemodialysis was required on three more occasions (Fig. 4). On the 2nd day he passed large quantities of clear watery fluid and faeces per rectum. The presence of a villous papilloma with oliguric renal failure was suspected and the fluid intake increased. Despite the early improvement in urinary output he could not be considered adequately hydrated and well until after the large fluid intake of the 18th, 19th and 20th days (Fig. 4). Sigmoidoscopy confirmed the diagnosis and barium X-ray studies showed that the tumour, situated at the recto-sigmoid junction, was the
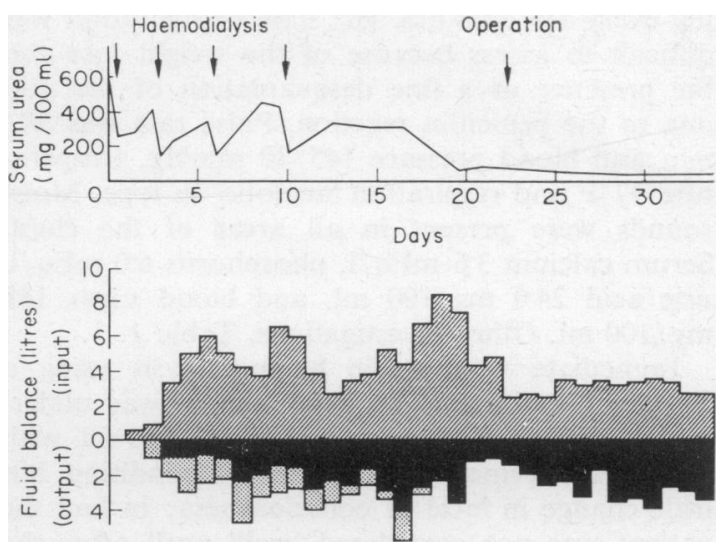

FIG. 4. Progress chart of Case 2. Cross-hatched area, Fluid intake (excluding blood); solid area, urine volume; stippled area, rectal loss.

only lesion present. No evidence of malignancy was found in a biopsy. Twenty days after admission a Hartmann's resection of the colon was performed (PDE) and he made an uneventful recovery. Histological examination of the specimen has shown no evidence of malignancy. Maximum diameter of the tumour $9 \mathrm{~cm}$ (Fig. 5).

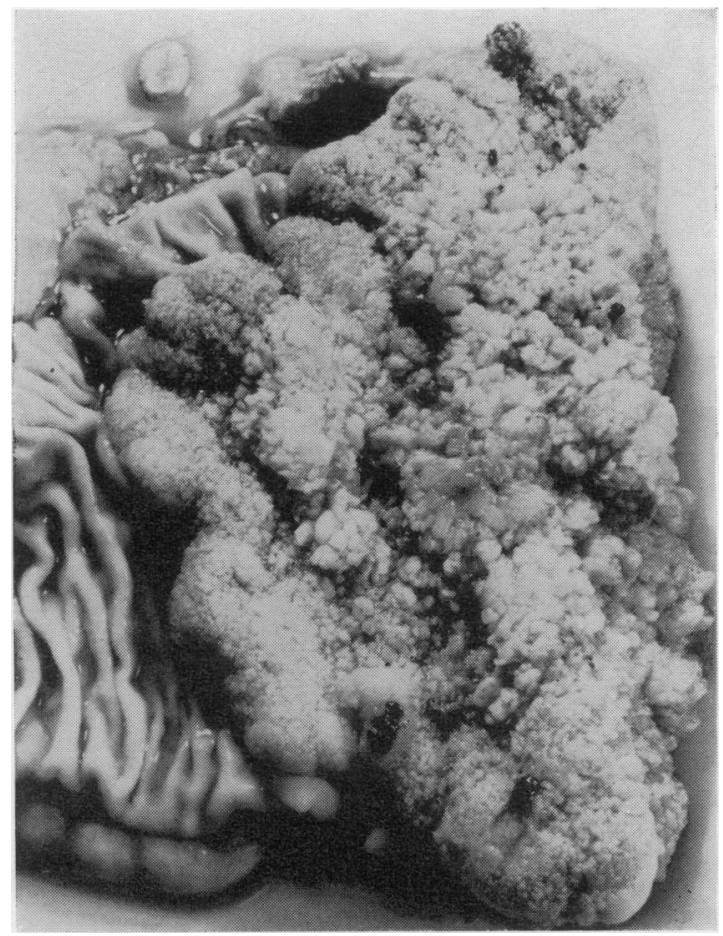

FIG. 5. Operative specimen (Case 2). Maximum diameter of the villous papilloma $9 \mathrm{~cm}$. 


\section{Discussion}

Villous papillomata of the large bowel (Figs. 2,5 and 6) occur predominantly in men in their fifth or sixth decade of life and account for $2 \%$ of all surgically removed neoplasms of the colon (Sunderland \& Binkley, 1948 ; Bacon et al., 1954 ;

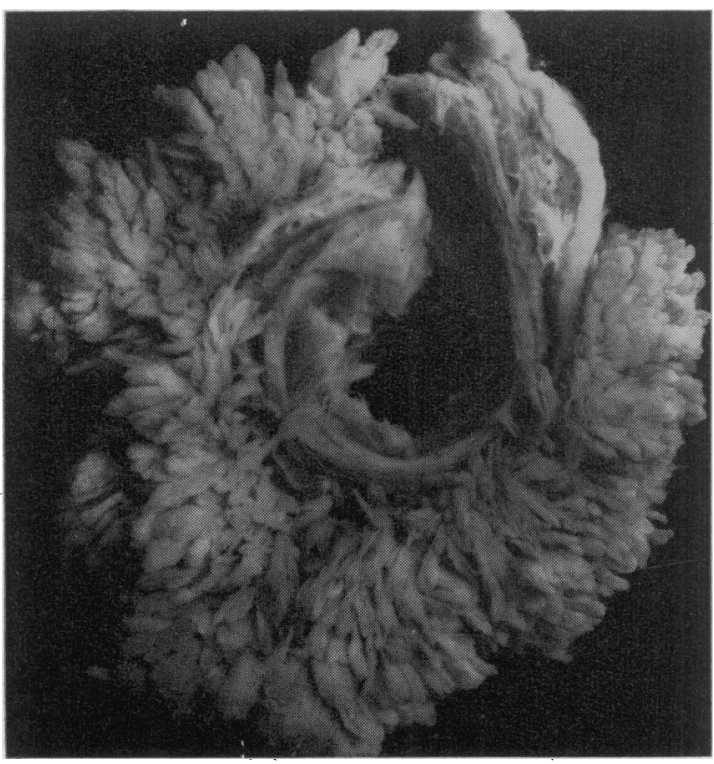

Fig. 6. Two-millimetre wide section of the tumour (Case 1), photographed floating in water to show the villi.

Mayfield \& Milnor, 1959). They are flat, soft, sessile growths of up to $13 \mathrm{~cm}$ in diameter and $80 \%$ are situated below the recto-sigmoid junction (Wheat \& Ackerman, 1958).

A small percentage of these villous papillomata lose considerable quantities of fluid and electrolytes per rectum. This creates certain difficulties in diagnosis. The long history of attacks of diarrhoea (average 5.4 years, Shnitka et al., 1961) sug- gests a 'colitis' or possibly a 'gastro-intestinal upset' if symptoms of dehydration and electrolyte depletion are added with abdominal colic, cramps, thirst and anorexia. 'Colitis', hysteria, hyperparathyroidism, diabetic coma, beri-beri, duodenal ulcer, cerebral abscess, Guillain-Barré syndrome, salt-losing nephritis and adreno-cortical insufficiency are some of the preliminary diagnoses entertained in reported cases where there has been gross biochemical and fluid imbalance.

Confirmation of the diagnosis depends entirely upon sigmoidoscopic and radiographic studies of the colon and rectum. Digital examination of the soft, velvety tumour is unreliable (Gabriel, 1952; Welch \& Dockerty, 1958) and the incidence of a second lesion in the large bowel has been reported as high as $30 \%$ (Wheat \& Ackerman, 1958 ; South wood, 1962).

During attacks of diarrhoea the volume and electrolyte content of the fluid lost per rectum varies from day to day and bears no relation to the patient's state of hydration nor to the level of the serum electrolytes (Table 2 and Fig. 4). Volumes up to $31 /$ day containing $50-200 \mathrm{mEq} / 1$ of sodium, $15-80 \mathrm{mEq} / 1$ of potassium and up to $160 \mathrm{mEq} / 1$ of chloride may be passed. This may be compared with the normal daily loss in the stool of $2.7 \mathrm{mEq}$ of sodium (Cooke et al., 1953), 10-15 mEq of potassium (Diffenbaugh et al., 1964) and less than $5 \mathrm{mEq}$ of chloride. Calcium and protein loss may be sufficient to produce tetany (Case 1) and a marked hypoproteinaemia (Cases 1 and 2).

The gradual and insidious onset of this disease allows the patient to compensate for the loss of fluid and electrolytes and the deficit may be enormous by the time he presents for treatment or collapses with acute-on-chronic hyponatraemia (Hoffmann, 1959; Shnitka et al., 1961), hypokalaemia or renal failure. Both our patients worked as labourers until a few days before their admission.

TABLE 2

Case 2: Daily output of sodium and potassium in urine and rectal fluid

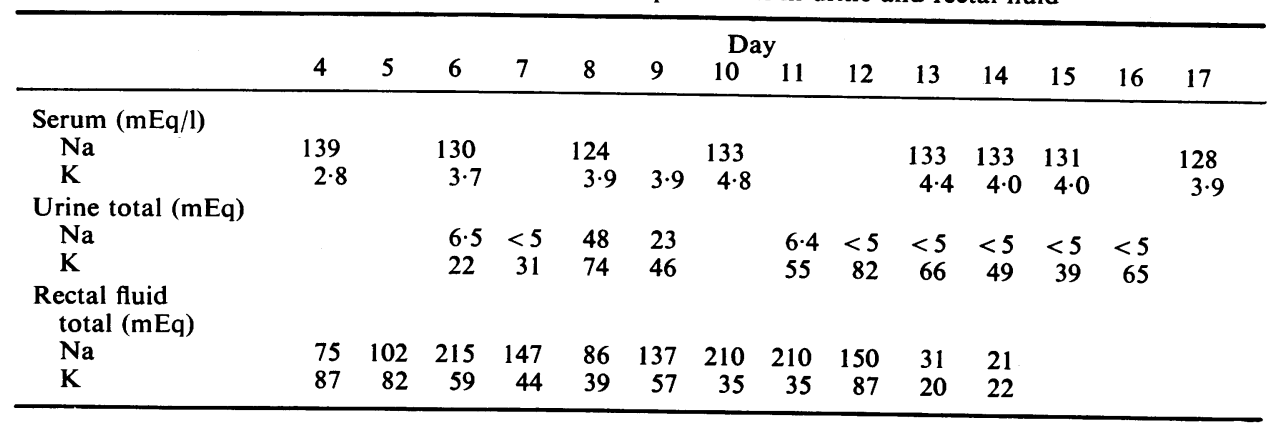


Treatment falls into two distinct phases, namely complete correction of the physiological disturbance followed by excision of the tumour. It is evident from a review of our two cases that we considerably underestimated the basic fluid and electrolyte deficit in the early days of treatment. This suggestion is supported by the improvement in the two patients after infusing 8-14 litres of fluid and $400-500 \mathrm{mEq}$ of potassium in excess of their output. We failed to appreciate the significance of a possible tubular nephropathy due to chronic electrolyte depletion, so that the quantity of urine passed and its electrolyte content led us to believe that they had been adequately resuscitated. The artificial kidney played a vital part in saving these two patients though the number of haemodialyses might have been reduced by earlier and more enthusiastic replacement therapy.

The type of operation to be performed will depend upon the incidence of malignancy in these rare tumours. Estimates vary from $6 \%$ to $75 \%$ (Sunderland \& Binkley, 1948; Fisher \& Castro, 1953 ; Wheat \& Ackerman, 1958; Mayfield \& Milnor, 1959; Diffenbaugh et al., 1964). Biopsy is a quite inadequate form of investigation as any malignant change tends to be focal and a positive result may be obtained in less than $6 \%$ of biopsies taken from tumours later proved to be malignant. Indeed histological examination of the excised neoplasm may require 150-200 sections before a malignant focus can be demonstrated (Fisher \& Castro, 1953). Such foci are more often found in the larger neoplasms and as the majority of the reported electrolyte- and fluid-losing tumours have a diameter of the order of $10 \mathrm{~cm}$ it would seem reasonable to treat them as if malignant (Sunderland \& Binkley, 1948; Gabriel, 1952; Wheat \& Ackerman, 1958; Mayfield \& Milnor, 1959). In practice the site and size of the tumour often dictate the type of operation carried out and, as in our own two cases, an abdomino-perineal or Hartmann's resection may be the only practical procedure.

\section{Summary}

The case reports of two patients are presented in whom renal failure was precipitated by electrolyte- and fluid-losing villous papillomata of the large bowel.
The diagnostic and therapeutic problems are discussed.

It is suggested that surgery should not be attempted until the gross depletion of all electrolytes and fluid has been corrected and that the tumour should be treated as a malignant neoplasm.

\section{Acknowledgments}

r We wish to thank the surgeons, ${ }^{r} \mathrm{Mr}$ Irvine B. Smith and Mr M. D. Lord, for referring these two cases to the Artificial Kidney Unit and also to acknowledge the help given by Mr Tom Dee, Clinical Photographer at the Queen Elizabeth Hospital.

\section{References}

Bacon, H.E., Lowell, E.J. \& Trimpi, H.D. (1954) Villous papillomas of the colon and rectum. Surgery, 35, 77.

Bamford, J.K., Galbraith, H.J.B. \& Pender, B.W.T. (1965) Villous adenoma of the rectum with electrolyte depletion, diabetes and hypogonadism. Postgrad. med.J. 41, 186.

Cooke, W.T., Thomas, G., Mangall, D. \& Cross, H. (1953) Observations on faecal excretion of total solids, nitrogen, sodium, potassium, water and fat in the steatorrhoea syndrome. Clin. Sci. 12, 223.

Davis, J.E., Seavey, P.W. \& Sessions, J.T. (1962) Villous adenomas of the rectum and sigmoid colon with severe fluid and electrolyte depletion. Ann. Surg. 155, 806.

Diffenbaugh, W.G., Strohl, E.L., Anderson, R.E. \& WoOdward, N. (1964) Papillary villous adenomas. Location in rectum and colon with electrolyte imbalance. Arch. Surg. 88, 577.

Fisher, E.R. \& CASTro, A.F. (1953) Diffuse papillomatous polyps of the colon and rectum. Amer.J. Surg. 85, 146.

GABRIEL, W.B. (1952) The surgical management of large villous tumours of the rectum. Proc. roy. Soc. Med. 45, 696.

Hoffman, E. (1959) Hyponatraemia due to a villous adenoma of the rectosigmoid. Amer. J. Surg. 98, 99.

MAYfield, L.H. \& MilnoR, J.P. (1959) Villous tumour of the rectum and a portion of the sigmoid flexure causing severe electrolyte imbalance. Dis. Colon Rect. 2, 311.

Shamblin, J.R., Huff, J.F., Waugh, J.M. \& Moertel, C.G. (1962) Villous adenocarcinoma of the colon with pronounced electrolyte disturbance. Ann. Surg. 156, 318.

ShNitKa, T.K., Friedman, N.H.W., Kidd, E.G. \& MACKENZIE, W.C. (1961) Villous tumours of the rectum and colon characterized by severe fluid and electrolyte loss. Surg. Gynec. Obstet. 112, 609.

Southwood, W.F.W. (1962) Villous tumours of the large intestine. Ann. roy. Coll. Surg. Engl. 30, 23.

Sunderland, D.A. \& Binkley, G.E. (1948) Papillary adenomas of the large intestine. Cancer, $1,184$.

WelCh, J.S. \& DOCKERTY, M.B. (1958) Villous carcinoma of the colon. Dis. Colon Rect. 1, 251.

WheAT, M.W. \& ACKerman, L.V. (1958) Villous adenoma of the large intestine. Ann. Surg. 147, 476. 